\title{
Manganese in long term paediatric parenteral nutrition
}

\author{
A P Reynolds, E Kiely, N Meadows
}

\begin{abstract}
The current practice of providing manganese supplementation to neonates on long term parenteral nutrition is leading to a high incidence of hypermanganesaemia. Magnetic resonance imaging (MRI) studies in adults on long term manganese parenteral nutrition have shown changes in TI weighted MRI images and similar findings in a neonate receiving trace element supplementation are reported here. Whole blood manganese concentration in the infant was 1740 nmol/1 (or 8.3 times upper reference limit). In all neonates on long term parenteral nutrition with evidence of cholestatic liver disease so far investigated, the whole blood manganese concentrations were $>360 \mathrm{nmol} / \mathrm{l}$ (reference range 73-210). Manganese supplementation to patients on long term parenteral nutrition requires reappraisal, particularly in those who develop cholestatic liver disease associated with parenteral nutrition.
\end{abstract}

(Arch Dis Child 1994; 71: 527-528)

Case history (case 1)

A 5 day old girl was admitted to the Hospital for Sick Children in London with bile stained vomiting. She was born prematurely at 35 weeks with intrauterine growth retardation and had been ventilated for aspiration pneumonia before transfer to this hospital. She underwent laparotomy on the day of admission when an 'apple-peel' type jejunal atresia was resected and intestinal continuity restored by primary anastomosis. Subsequently, due to adhesion obstruction, all but $7 \mathrm{~cm}$ of her small bowel was removed. In consequence parenteral nutrition was instituted together with enteral feeding via a nasogastric tube. After three months of parenteral nutrition, her liver function tests indicated parenteral nutrition associated cholestatic liver disease. At 7 months of age, concerns arose regarding developmental delay, abnormal dystonic movements of both arms, and microcephaly. At 12 months of age, both developmental progress and head circumference appeared to stop. Magnetic resonance imaging (MRI) showed basal ganglia changes compatible with deposition of a paramagnetic trace metal such as iron. An abnormality in iron metabolism was ruled out by normal concentrations of serum ferritin.

The progression of parenteral nutrition associated liver disease was indicated by increased plasma values of both bilirubin and aspartate aminotransferase. Serum concentrations of trace metals, including copper, selenium, and zinc had been monitored throughout and remained within the normal range. Manganese was finally included in an investigation carried out when the infant was 17 months old. The result showed a high blood manganese concentration of $1740 \mathrm{nmol} / 1$ (reference range $73-210 \mathrm{nmol} / \mathrm{l}$ ). At 18 months her condition deteriorated and after readmission, neurological review indicated a poor prognosis and she died peacefully.

\section{Discussion}

The recognition that manganese is an essential trace element ${ }^{1}$ has led to its incorporation into parenteral solutions. Balance studies suggested a daily dietary requirement of $0.7-2.5 \mathrm{mg}$ in adults $^{2}$ but, given the methods then used for analysis of trace elements, these figures were probably at best a crude estimate. In 1988, the American Society for Clinical Nutrition issued recommendations for paediatric parenteral nutrition, including newborn infants, of $1 \mu \mathrm{g}$ manganese/kg pending further data on growth requirements. $^{3}$

In the UK, manufacturers of multielemental solutions have recommended that babies weighing less than $10 \mathrm{~kg}$ should receive a daily manganese supplement of $44-55 \mu \mathrm{g} / \mathrm{kg}$ $(800-1000 \mathrm{nmol} / \mathrm{kg}){ }^{4}$ This amount is 55 times higher than the American Society for Clinical Nutrition recommended in 1988.

Liver disease is a well recognised complication, of unknown aetiology, in patients on long term parenteral nutrition. In contrast to copper, whether manganese accumulation may be hepatotoxic in man is not known. Evidence that it may be hepatotoxic has come from studies in rats injected intravenously with manganese solutions. This resulted in a mild but reversible episode of intrahepatic cholestasis. When manganese 'overload' was subsequently followed by infusions of bilirubin, the lesions increased in severity as the doses of bilirubin infused increased. ${ }^{5}$ Manganese could therefore be a major and overlooked causative factor, as the metal is excreted via the biliary system. ${ }^{6}$

It seems that excess manganese may also accumulate in other tissues, for example, in brain. Ejima et al reported an adult patient on long term parenteral nutrition with high serum manganese who exhibited parkinsonian movements. ${ }^{7}$ These stopped when manganese concentrations became normal after manganese supplements were stopped. Mirowitz et al observed a symmetrically increased signal intensity on $\mathrm{T} 1$ weighted MRI in the basal ganglia of nine adult patients 
Postmortem tissue analysis of manganese in case 2 (assayed by SAS Trace Metals Unit, Institute of Biochemistry, Royal Infirmary, Glasgow in 1989). Tissue concentrations are not age related reference ranges due to limited data available

\begin{tabular}{llc}
\hline Tissue & Mean $(S D)$ reference value $(\mu \mathrm{g} / \mathrm{g})$ & Case 2 \\
\hline Muscle & $0 \cdot 24(0 \cdot 06)$ & $1 \cdot 8$ \\
Heart & $1 \cdot 15(0 \cdot 42)$ & $2 \cdot 4$ \\
Kidney & $5 \cdot 90(1 \cdot 60)$ & $5 \cdot 5$ \\
Liver & $5 \cdot 80(2 \cdot 00)$ & $14 \cdot 7$ \\
\hline
\end{tabular}

on long term parenteral nutrition (mean $=5 \cdot 3$ years) without evidence of hepatic dysfunction. ${ }^{8}$ In one of these patients, the abnormal signal intensity regressed when parenteral manganese administration was stopped after one year. ${ }^{9}$ It is unclear to what extent the basal ganglia in neonates and infants are affected, and whether these changes are reversible. It is noteworthy that basal ganglia changes were demonstrated in our patient. It now seems expedient to monitor whole blood manganese concentrations in infants receiving parenteral nutrition.

A previous patient (case 2) who had microvillous atrophy and was on long term parenteral nutrition died in 1989. She had presented with hypoglycaemic episodes and was investigated for six trace elements in postmortem tissues (table). The results showed accumulation of aluminium, chromium, and manganese. At the time, the potential significance of these manganese findings was overlooked.

As a result of our findings in case 1 , we have now investigated 53 children who have been on parenteral nutrition for more than six weeks and have found manganese concentrations $>360 \mathrm{nmol} / \mathrm{l}$ in all those who had biochemical evidence of cholestatic liver disease (35/53). One child with short gut syndrome, who had been on parenteral nutrition since shortly after birth, developed associated liver disease and whole blood manganese on day 51 was 1037 $\mathrm{nmol} / \mathrm{l}$. The highest concentrations of blood manganese were found in infants $<2$ years of age; these infants were all receiving parenteral nutrition (Ped-El, Pharmacia Ltd; figure). The biliary excretion of manganese in this age group may also be less efficient.

\section{Conclusion}

We recommend the following in patients on parenteral nutrition: blood concentrations of manganese need to be monitored on a regular basis and any evidence of cholestatic liver disease should be evaluated taking the manganese concentration into consideration. We suggest that MRI should be carried out in children who have persistent concentrations of whole blood manganese $>360 \mathrm{nmol} / \mathrm{l}$ to

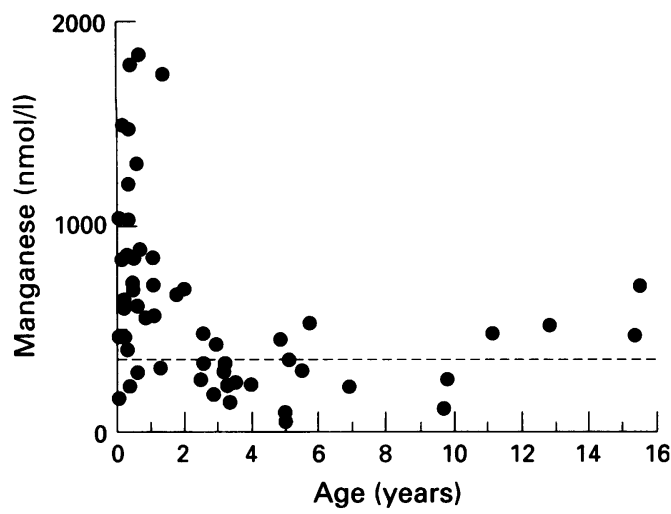

Whole blood manganese concentrations and age in infants and children on parenteral nutrition receiving either Ped-El or Addamel. Values above the dotted line are >360 nmoll.

monitor the development and function of the basal ganglia.

Reducing the parenteral administration of manganese could in theory induce hypomanganesaemia. However, there is only a single case reported in the literature of manganese deficiency; this involved an individual on an experimental diet. ${ }^{10}$ In patients on long term parenteral nutrition, regular monitoring of whole blood manganese concentrations should eliminate this possibility.

Following these findings, Pharmacia Ltd have now (i) issued new guidelines on the use of Ped-El; (ii) issued Peditrace which contains $1 \mu \mathrm{g} / \mathrm{kg}$ manganese in line with the American Society for Clinical Nutrition recommendations. This product, which will replace Ped-El, is awaiting a product licence and is currently issued on a named patient basis only; and (iii) withdrawn Addamel from clinical use.

We thank Dr H T Delves, department of chemical pathology, General Hospital, Southampton, for providing the majority of manganese assays in this study.

1 Burch RE, Sullivan JF. Diagnosis of zinc, copper and manganese abnormalities in man. Med Clin North Am 1976; 60: 655-60

2 WHO expert committee report. Trace elements in human nutrition. World Health Organ Tech Rep Ser 1973; 532 1070 .

3 Guidelines for paediatric parenteral nutrition. Committee on clinical practice issues of the American Society for Clinical Nutrition. Am f Clin Nutr 1988; 48: 1324-42.

4 Ball PA, Booth IW, Holden CE, Puntis JWL. Paediatric parenteral nutrition. Uxbridge: Pharmacia Ltd, 1994.

5 Ayotte P, Plaa GL. Hepatic subcellular distribution of manganese and manganese-bilirubin induced cholestasis. Biochem Pharmacol 1985; 34: 3857-65.

6 Versieck J. Serum and packed blood cell manganese, copper and zinc concentrations in normal controls and patients with hepatobiliary disease [Thesis]. Ghent, Belgium Akademisch Ziekenhuis, 1975 .

7 Ejima A, Imamura T, Nakamura S. Manganese intoxication

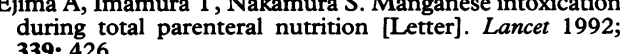

8 Mirowitz SA, Westrich TJ, Hirsch JD. Hyperintense basal ganglia on T1-weighted MR images in patients receiving parenteral nutrition. Radiology 1991; 181: 117-20.

9 Mirowitz SA, Westrich TG. Basal ganglial signal intensity alterations: reversal after discontinuation of parenteral manganese administration. Radiology 1992; 185: 535-6.

10 Doisy EA. Trace elements in environmental health. Vol VI. University of Missouri, 1972: 193-4. 